\title{
Recombinant Inbred Strain
}

National Cancer Institute

\section{Source}

National Cancer Institute. Recombinant Inbred Strain. NCI Thesaurus. Code C14374.

Recombinant inbred (RI) strains are derived by systematic inbreeding from the cross of two pre-existing progenitor strains. (from JAX Strain Information) 